\title{
Development of Novel Computer Program for Cycle Analysis of Turbojet Engine
}

\author{
Moaz Hussain, P. Deepak Kumar, S.R. Arun, Vismaya, P. Hari Siva
}

\begin{abstract}
A method to simulate the gas turbine cycle and performance is developed. This paper intent to describe a digital computer code to make it useful for other researchers. This program is written in Python language for analyzing the steady-state, parametric cycle performance of turbojet engines. This can be used to analyze one- and two-spool turbojet engines without any modification to the basic program. The influence of initial parameters, component characteristics and flight condition on performance characteristics of gas turbine during operation are shown. The program results are compared and validated with those from an existing GSP (Gas Turbine Simulation Program) software. The major advantage of this new method is that it frees the programmer from having to minimize the number of equations which require iterative solution. As a result, some of the approximations normally used in engine simulations can be eliminated. The outcomes of this analysis form a strong base for further analysis to predict the performance of the gas turbine engine with reasonable accuracy for design and fabrication of gas turbine engines using this performance code.
\end{abstract}

Keywords : Cycle Analysis, GSP, Python, Thrust, Turbojet Engine.

\section{INTRODUCTION}

Computer programs which predict the performance of theoretical engines have long been recognized as valuable tools for preliminary and detail design work. Digital computer codes enable the user to analyze the steady-state performance of a wide variety of engines simply by providing component performance and other pertinent data [1]. Aircraft gas turbine performance can be determined by cycle analysis as these analyses provide vital data that can be used for the actual design and testing of the components.

Revised Manuscript Received on February 28, 2020.

* Correspondence Author

Moaz Hussain*, Department of Aeronautical Engineering, Excel Engineering College, Erode, Tamil Nadu, India. Email: moazhussain00.mh@gmail.com

P. Deepak Kumar, Department of Aeronautical Engineering, Excel Engineering College, Erode, Tamil Nadu, India. Email: deepakkumarpandiyan@gmail.com

S.R. Arun, Department of Aeronautical Engineering, Excel Engineering College, Erode, Tamil Nadu, India. Email: srarun900@gmail.com

Vismaya, Department of Aeronautical Engineering, Excel Engineering College, Erode, Tamil Nadu, India.

P. Hari Siva, Department of Aeronautical Engineering, Excel Engineering College, Erode, Tamil Nadu, India.

(C) The Authors. Published by Blue Eyes Intelligence Engineering and Sciences Publication (BEIESP). This is an open access article under the CC-BY-NC-ND license http://creativecommons.org/licenses/by-nc-nd/4.0/
Also, it provides the differing requirements for take-off, climb, cruise and maneuvering to the designer of aircraft engines [2]. The cycle analysis program deals with the thermodynamic changes of the working fluid (air and products of combustion in most cases) as it flows through the engine [3]. The cycle analysis (also known as design-point or on-design) determines the performance of engines at different flight conditions and values of design choice (e.g., compressor pressure ratio) and design limit (e.g., combustor exit temperature) parameters [4]. Nowadays computer models and simulation using commercial software like GasTurb, GSP, NPSS, etc., have been widely used but the licensed versions are expensive. Hence, for simplifying the procedure of cycle analysis a computer program was developed in Python language. This user-friendly program calculates the cycle parameters at each node of the engine along with the net thrust produced, specific thrust, nozzle characteristics, exhaust area required, propulsive efficiency and specific fuel consumption of engine at the range of inputs (operating condition and component efficiencies) provided to it.

\section{RESEARCH METHODOLOGY}

The development of the performance analysis code starts with the understanding of the basic concepts of jet engine theory. Empirical relations were used to calculate various parameters of turbojet engines. The language chosen for this work was Python which has a linage of versions and here Python 3.8 was used. It has enhanced data type facilities with simple elegant syntax suitable for scientific and numeric computing.

\section{A. Basic Equations}

The underlying concept in calculating the performance of jet engine falls between the energy generated and its consumption. The power produced between the components will account for the net thrust at static and dynamic flight conditions. We can express the thrust as a function of the engine pressure ratio and the ratio of specific heat $(\gamma)$.

$$
\begin{aligned}
& \frac{F}{A_{5} * p_{a}}=K[E P R]-1 \\
& \left(\frac{F}{A_{5} * p_{a}}+1\right) /_{R P R}=K[E P R]
\end{aligned}
$$

The above relationship shows the thrust for static condition in (1) and for dynamic condition in (2). Where RPR is Ram Pressure Ratio, EPR is Engine Pressure Ratio and $K=f(\gamma)$. The value for $K=1.2594$ for $\gamma=1.333$.

$$
T I T=T_{c}+\frac{f * \mathrm{CV}^{2} \eta_{b}}{c_{p}}
$$


The turbine inlet temperature (TIT) can be related to compressor outlet temperature $\left(\mathrm{T}_{\mathrm{c}}\right)$, fuel-air ratio $(\mathrm{f})$, isobaric heat capacity $\left(\mathrm{c}_{\mathrm{p}}\right)$, calorific value of fuel $(\mathrm{Cv})$ and combustion efficiency $\left(\eta_{b}\right)$. The remaining equations are also used from [2].

\section{B. Simulation Model}

The simulation of a physical system involves- setting up of a model and investigation of the behavior of this model. In a turbojet engine, air is taken in through an opening in the front of the engine which is compressed in the compressor. Fuel is added to the air and burnt in the combustion chamber to raise the temperature of the fluid mixture. The resulting hot air is passed through a turbine, which drives the compressor and the exhaust gasses passes through a nozzle outlet where thrust is produced because of the reactive forces. The main components of a turbojet engine are: a) Inlet Duct b) Compressor c) Combustion chamber d) Turbine e) Outlet Nozzle pipe.

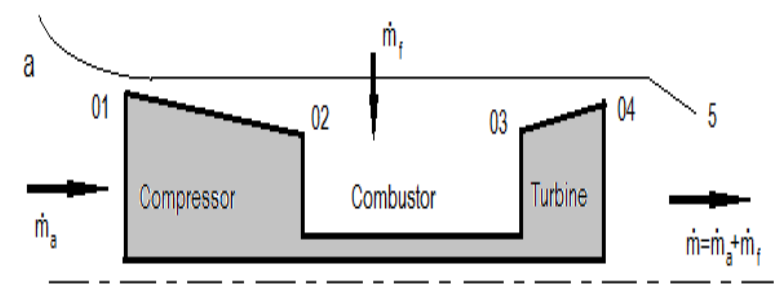

Fig. 1 Single spool turbojet engine model

The model used for development of computer program is provide in Fig. 1 shows components of single spool turbojet engine. The intake (node ' $a$ ' to ' 01 '), compressor section is connected to turbine by a spool and the exhaust nozzle (node '04' to '5') are the components shown. Fig. 2 shows components of dual spool turbojet engine. The intake (node ' $a$ ' to ' 01 '), low pressure compressor is connected to low pressure turbine by a shaft, high pressure compressor connected to high pressure turbine with second shaft and the exhaust nozzle (node '06' to '7') are the components shown.

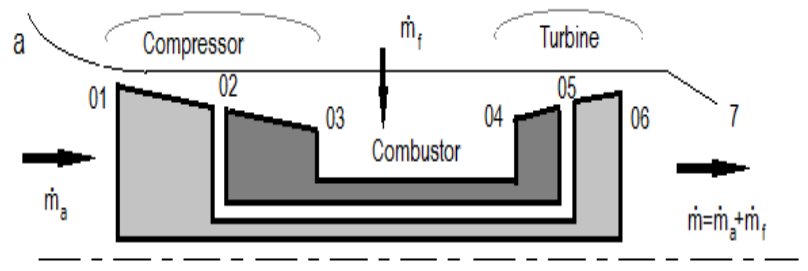

Low pressure section

High pressure section

Fig. 2 Dual-spool turbojet engine model

\section{GSP Model}

Validation of parametric analysis of a single- and dual-spool turbojet engine is performed using NLR's Gas turbine Simulation Program (GSP-11), an off-line component-based modeling environment for gas turbines which is widely used to perform the steady state simulation of the scaled engine. The model was designed in GSP similar to those of programmed model. Fig. 2 (a \& b) shows the designed single- spool and dual-spool engine model in GSP software respectively.

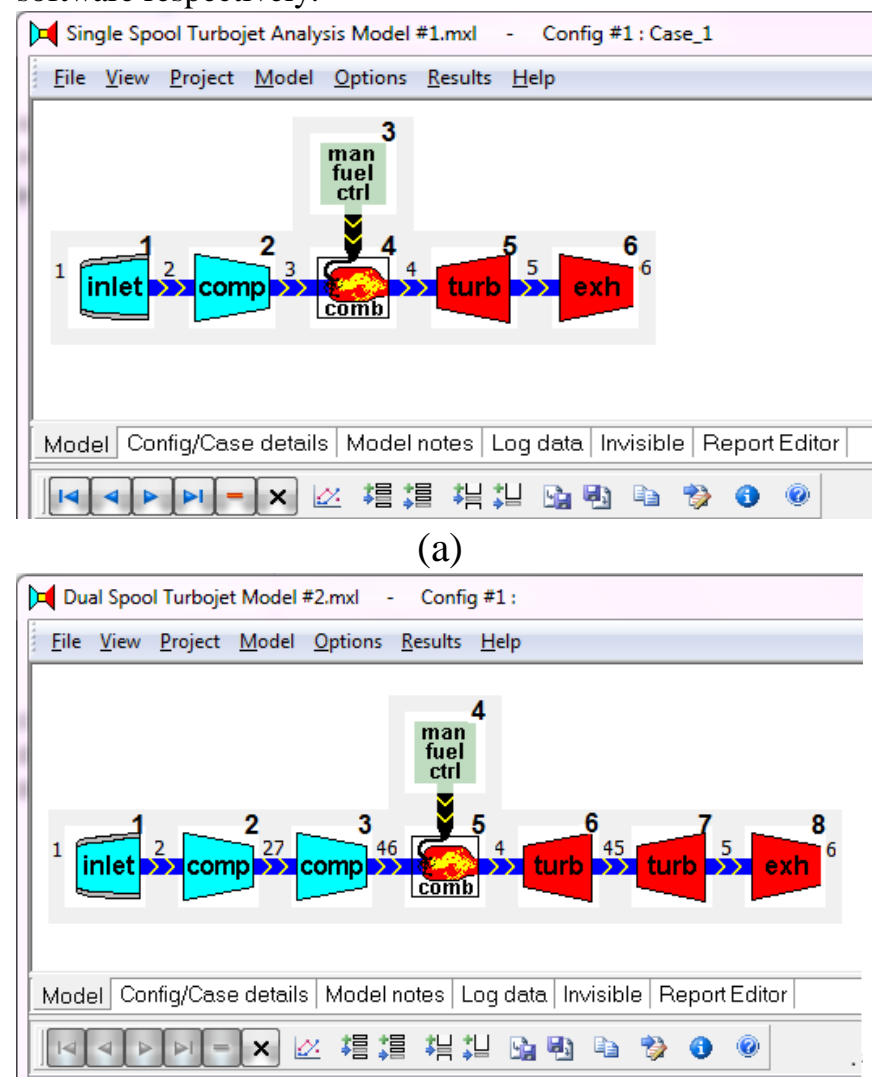

(b)

Fig. 3 GSP model of single-spool (a) and dual-spool (b) turbojet engine

\section{RESULT AND VALIDATION}

The developed program was used to analyses the cycle performance of the engine at various operating condition and the results obtained from the analysis was further compared with the results obtained from the GSP software simulation. The results are tabulated with error percentage and also provided in graphical representation.

\section{A. Single-spool analysis}

The single-spool analysis was done on a simple turbojet engine operating at an altitude of $10,000 \mathrm{~m}$. the component efficiencies are taken from the historical data [2]. The comparison of data obtained from analysis and GSP software was carried out for operating speed of 0.8 Mach, compressor pressure ratio (PR) of 8, air mass flow rate of $20 \mathrm{Kg} / \mathrm{s}$. The fuel-air ratio was taken as 0.018 and calorific value $(\mathrm{Cv})$ of fuel used for combustion as $44,500 \mathrm{KJ} / \mathrm{Kg}$. the combustion pressure loss of 0.3 bar was also taken into account.

\section{a. Thrust produced at various Mach number:}

The thrust is calculated using the customary equation (1 and 2) for impulse reaction force of the flow plus the static pressure difference from throat to ambient pressure times the throat area. The comparative data of produced thrust at various Mach number is provided in Table- I and also in Fig. 4. 


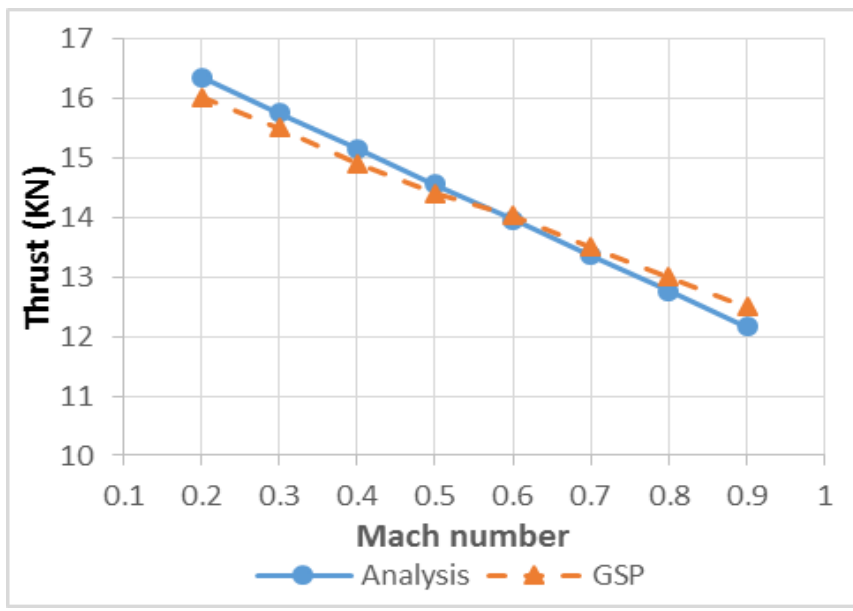

Fig. 2 Variation of thrust at changing Mach number in single-spool engine

Table- I. Comparison of thrust produced at different Mach number

\begin{tabular}{|r|r|r|r|}
\hline \multicolumn{1}{|c|}{ Mach } & \multicolumn{1}{c|}{ Analysis } & \multicolumn{1}{c|}{ GSP } & \multicolumn{1}{c|}{ \% error } \\
\hline 0.2 & 16.36 & 16.01 & 0.022 \\
\hline 0.3 & 15.76 & 15.50 & 0.017 \\
\hline 0.4 & 15.16 & 14.90 & 0.017 \\
\hline 0.5 & 14.56 & 14.40 & 0.011 \\
\hline 0.6 & 13.96 & 14.03 & -0.003 \\
\hline 0.7 & 13.36 & 13.50 & -0.011 \\
\hline 0.8 & 12.76 & 13.00 & -0.019 \\
\hline 0.9 & 12.16 & 12.50 & -0.027 \\
\hline
\end{tabular}

It was seen that the difference in results from the analysis of the developed program and GSP simulation at pressure ratio (PR) of 8 is very less and acceptable. The analysis was further carried out at different compressor pressure ratios (PR) and provided in appendix.

b. Thrust produced at various fuel-air ratio:

The effect of thrust produced at various mass flow rates of inlet air was also studied. The variation of net thrust with varying fuel-air ratios is shown in Fig. 6. The obtained values from analysis and simulation were tabulated and compared as provided in Table- II. The analysis was further carried out at different fuel-air ratios and air mass flow rates (m) and provided in appendix.

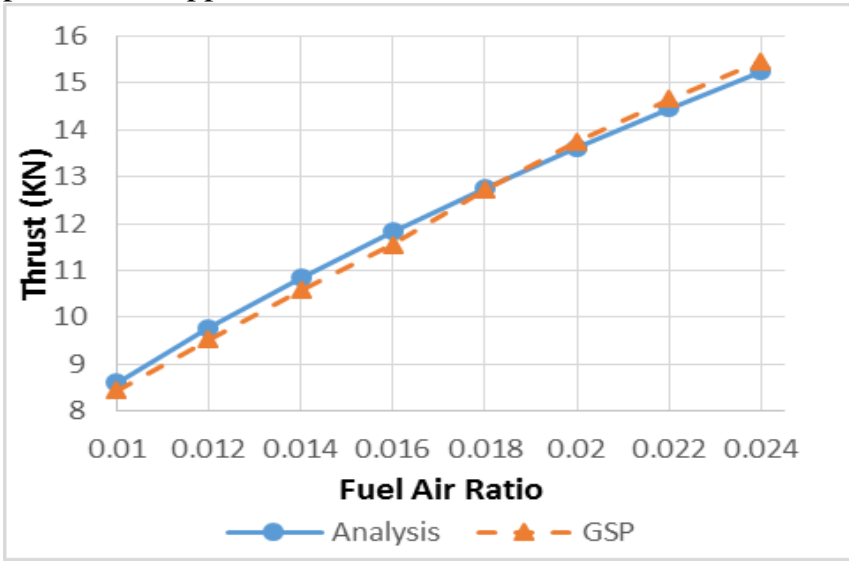

Fig. 3 Variation of thrust at changing fuel-air ratio in single-spool engine

Table- II. Comparison of thrust produced at different fuel-air ratio

\begin{tabular}{|r|r|r|r|}
\hline \multicolumn{1}{|c|}{ Fuel-air ratio } & \multicolumn{1}{c|}{ Analysis } & \multicolumn{1}{c|}{ GSP } & \multicolumn{1}{c|}{ \% error } \\
\hline 0.010 & 8.61 & 8.45 & 0.019 \\
\hline 0.012 & 9.78 & 9.53 & 0.026 \\
\hline 0.014 & 10.84 & 10.58 & 0.025 \\
\hline 0.016 & 11.83 & 11.55 & 0.024 \\
\hline 0.018 & 12.76 & 12.72 & 0.003 \\
\hline 0.020 & 13.63 & 13.76 & -0.010 \\
\hline 0.022 & 14.46 & 14.65 & -0.013 \\
\hline 0.024 & 15.25 & 15.47 & -0.014 \\
\hline
\end{tabular}

It is inferred from the above figure that the net thrust increases for an increase in the fuel-air ratio. The maximum error \% was found to be 0.026 which is acceptable.

c.Specific fuel consumption at various fuel flow rates $(\mathrm{mf})$ :

The Thrust Specific Fuel Consumption (TSFC) of the engine at various fuel flow rates is shown in Fig. 6. It is seen that the TSFC is maximum when the fuel supply is maximum in this study. The obtained values from analysis and simulation were tabulated and compared as provided in Table- III which shows the maximum error \% as 0.026 . The analysis was continued with changing Mach number. The result shows that TSFC also gets increased with an increase in Mach number which is provided in appendix.

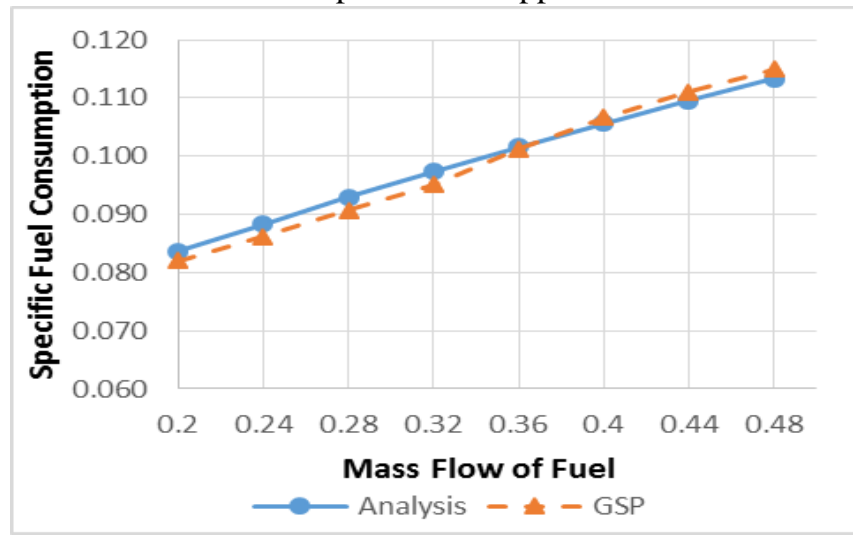

Fig. 4 Variation of specific fuel consumption at changing mass flow rate of fuel in single-spool engine

Table- III. Comparison of TSFC at different mass flow rate of fuel (mf)

\begin{tabular}{|r|r|r|r|}
\hline \multicolumn{1}{|c|}{$\mathbf{m f}$} & \multicolumn{1}{c|}{ Analysis } & \multicolumn{1}{c|}{ GSP } & \multicolumn{1}{l|}{ \% error } \\
\hline 0.2 & 0.084 & 0.082 & 0.019 \\
\hline 0.24 & 0.088 & 0.086 & 0.026 \\
\hline 0.28 & 0.093 & 0.091 & 0.025 \\
\hline 0.32 & 0.097 & 0.095 & 0.024 \\
\hline 0.36 & 0.102 & 0.101 & 0.003 \\
\hline 0.4 & 0.106 & 0.107 & -0.010 \\
\hline 0.44 & 0.110 & 0.111 & -0.013 \\
\hline 0.48 & 0.113 & 0.115 & -0.014 \\
\hline
\end{tabular}




\section{d. Temperature variation across engine components:}

The temperature variation in the working fluid as it flows through the engine is an important parameter that dictates the selection of material to the manufacturer for the particular component. The maximum temperature prevails in the combustion chamber and turbine where the combustion and the subsequent expansion take place. As there is a major setback on the availability of material that can withstand high temperatures, the analysis is performed to check the maximum temperature attained during the analysis for all the input conditions. A typical temperature profile across the engine components for a Mach operation of 0.8 at $10000 \mathrm{~m}$ altitude is given in Fig. 7.

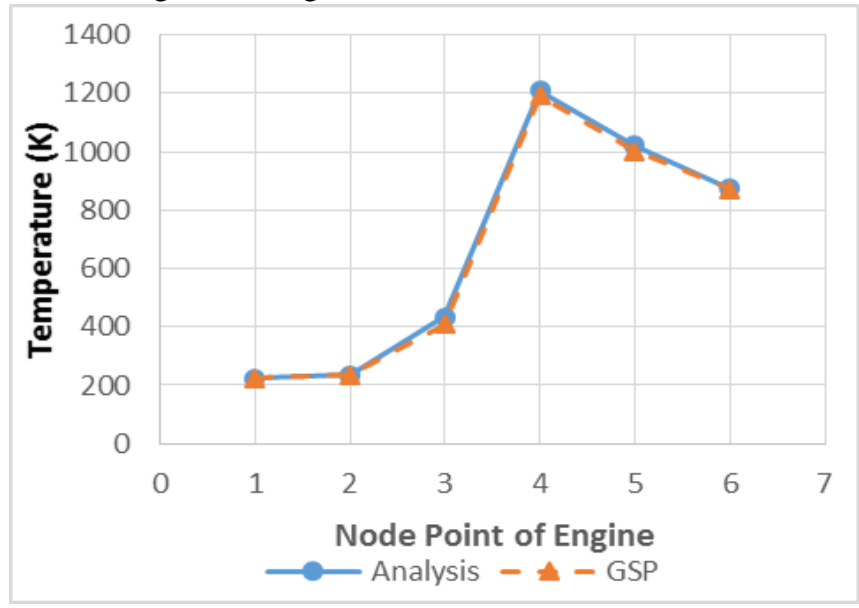

Fig. 5 Temperature variation along the engine components in single-spool engine

The node 1, 2 and 3 denotes ambient, compressor inlet and compressor outlet (combustor inlet) temperature of air respectively. The nodes 4,5 and 6 are the turbine inlet, nozzle duct, and exhaust temperature respectively. The comparative data in Table- IV. shows that upto compressor inlet the analysis and GSP calculations are same but the error \% was maximum (0.066) at compressor outlet as the GSP model considers a differential bleed during compression.

Table- IV. Temperature $(\mathrm{K})$ variation at various nodes

\begin{tabular}{|r|r|r|r|}
\hline \multicolumn{1}{|c|}{ Node } & \multicolumn{1}{|c|}{ Analysis } & \multicolumn{1}{c|}{ GSP } & \multicolumn{1}{c|}{ \% error } \\
\hline 1 & 223.3 & 223.3 & 0.000 \\
\hline 2 & 234.3 & 234.3 & 0.000 \\
\hline 3 & 435.31 & 408.39 & 0.066 \\
\hline 4 & 1208.42 & 1192.34 & 0.013 \\
\hline 5 & 1020.93 & 1002.65 & 0.018 \\
\hline 6 & 875.21 & 871.94 & 0.004 \\
\hline
\end{tabular}

\section{B. Dual-spool Analysis}

The analysis of dual-spool turbojet engine was carried out as per the parameters similar to single-spool analysis (section IV.A). In dual-spool we have two stages of compression and expansion as low pressure and high pressure section. The overall pressure ratio (OPR) was taken as 20, low pressure ratio (LPR) of 4 and high pressure ratio (HPR) of 5 was taken.

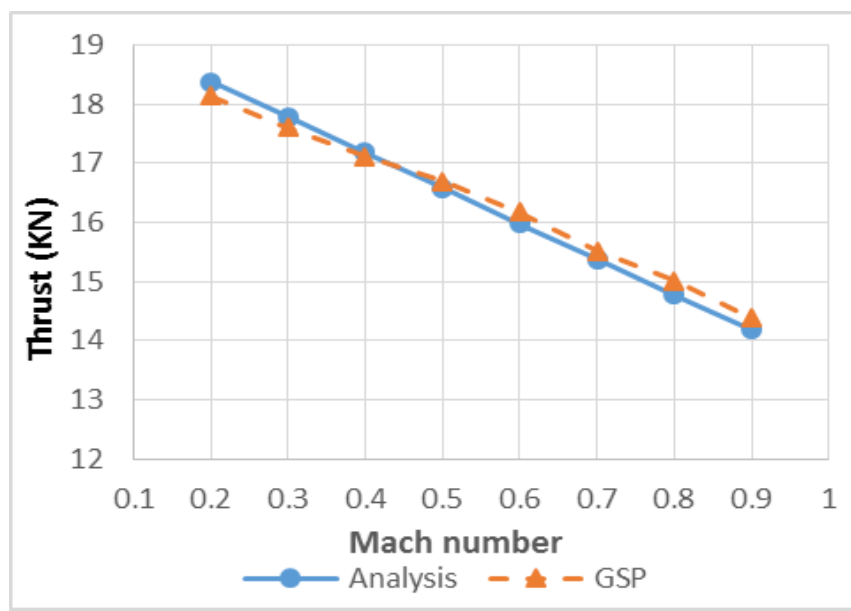

Fig. 6 Variation of thrust at changing Mach number in dual-spool engine

Table- V. Comparison of thrust produced at different Mach number

\begin{tabular}{|r|r|r|r|}
\hline \multicolumn{1}{|c|}{ Mach } & \multicolumn{1}{c|}{ Analysis } & \multicolumn{1}{c|}{ GSP } & \multicolumn{1}{c|}{ \% error } \\
\hline 0.2 & 18.38 & 18.14 & 0.013 \\
\hline 0.3 & 17.78 & 17.61 & 0.010 \\
\hline 0.4 & 17.18 & 17.12 & 0.004 \\
\hline 0.5 & 16.58 & 16.7 & -0.007 \\
\hline 0.6 & 15.98 & 16.18 & -0.012 \\
\hline 0.7 & 15.38 & 15.52 & -0.009 \\
\hline 0.8 & 14.78 & 15.01 & -0.015 \\
\hline 0.9 & 14.18 & 14.39 & -0.014 \\
\hline
\end{tabular}

The analysis was continued by keeping the Mach number constant at 0.8 and varying the fuel-air ratio (f) from 0.01 to 0.024 . The comparative data was obtained at $20 \mathrm{Kg} / \mathrm{s}$ mass flow of air from GSP and analysis. The results are provided in Fig. 9 for comparison. Values obtained from analysis and simulation are tabulated along with the error \% in Table- VI.

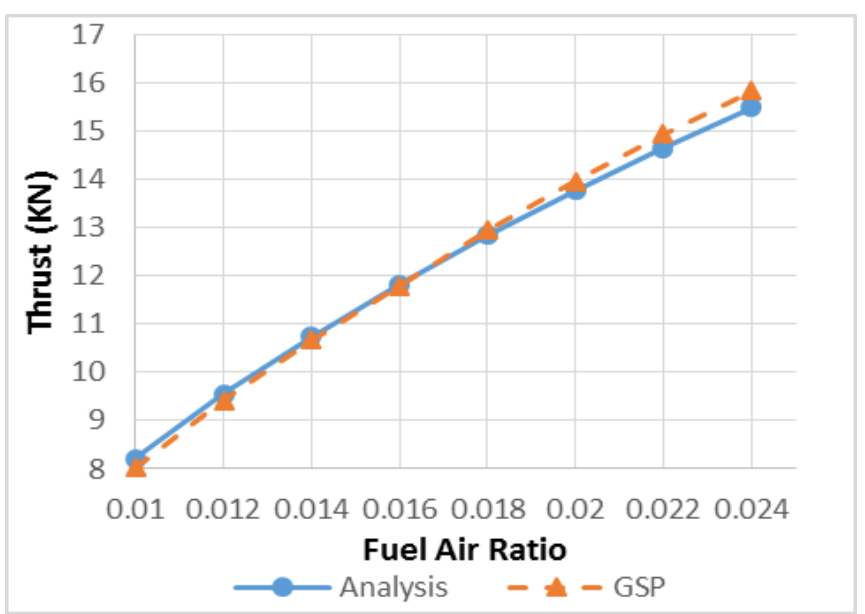

Fig. 7 Variation of thrust at changing fuel-air ratio in dual-spool engine 
Table- VI. Comparison of thrust produced at different fuel-air ratio

\begin{tabular}{|r|r|r|r|}
\hline \multicolumn{1}{|c|}{ Fuel-Air Ratio } & \multicolumn{1}{c|}{ Analysis } & \multicolumn{1}{c|}{ GSP } & \multicolumn{1}{c|}{ \% error } \\
\hline 0.01 & 8.22 & 8.03 & 0.023 \\
\hline 0.012 & 9.56 & 9.42 & 0.015 \\
\hline 0.014 & 10.75 & 10.68 & 0.007 \\
\hline 0.016 & 11.83 & 11.8 & 0.003 \\
\hline 0.018 & 12.84 & 12.94 & -0.008 \\
\hline 0.02 & 13.77 & 13.96 & -0.013 \\
\hline 0.022 & 14.65 & 14.94 & -0.019 \\
\hline 0.024 & 15.49 & 15.83 & -0.021 \\
\hline
\end{tabular}

Further, the variation of specific fuel consumption was studied at different mass flow rates of fuel. The result from the developed analysis program was compared with that of GSP simulation at fixed mass flow rate of air and flight Mach number of $20 \mathrm{Kg} / \mathrm{s}$ and 0.8 Mach respectively. Fig. 10 shows the graph plotted from the comparative data obtained and tabulated in Table- VII.

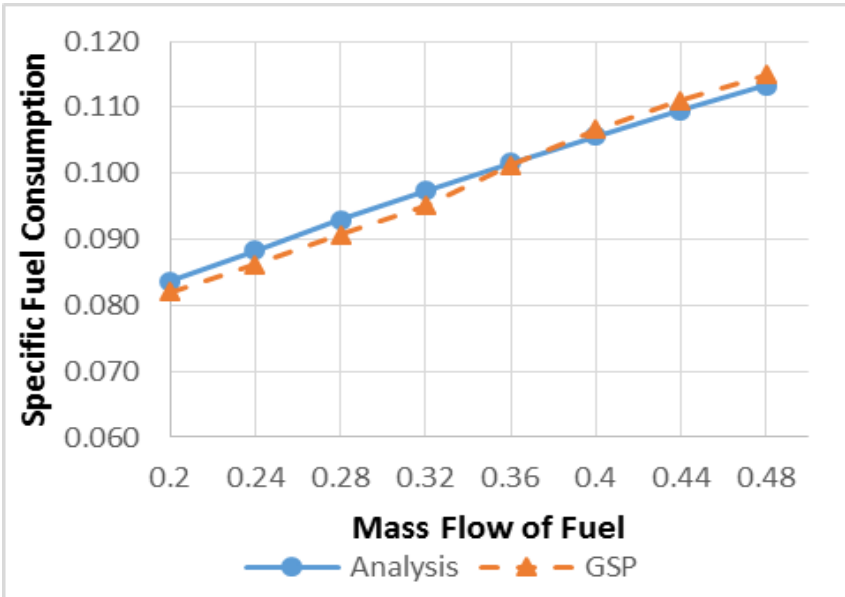

Fig. 8 Variation of specific fuel consumption at changing the mass flow rate of fuel in dual-spool engine

Table- VII. Comparison of SFC at different mass flow rate of fuel ( $\mathrm{mf})$

\begin{tabular}{|r|r|r|r|}
\hline \multicolumn{1}{|c|}{$\mathbf{~ m f}$} & \multicolumn{1}{c|}{ Analysis } & \multicolumn{1}{c|}{ GSP } & \multicolumn{1}{c|}{ \% error } \\
\hline 0.2 & 0.0836 & 0.082 & 0.020 \\
\hline 0.24 & 0.0884 & 0.087 & 0.022 \\
\hline 0.28 & 0.0929 & 0.092 & 0.010 \\
\hline 0.32 & 0.0974 & 0.097 & 0.000 \\
\hline 0.36 & 0.1016 & 0.103 & -0.014 \\
\hline 0.4 & 0.1057 & 0.108 & -0.022 \\
\hline 0.44 & 0.1096 & 0.112 & -0.022 \\
\hline 0.48 & 0.1133 & 0.116 & -0.023 \\
\hline
\end{tabular}

The calculated temperature across each component of the engine was also compared for detailing the error \%. A dual-spool engine is having more node points than that of a single-spool engine. The addition of one extra stage in an engine can increase one compression stage and one expansion stage, henceforth the node points from 6 (in single-spool) to 8 . The result is shown in Fig. 11 and tabulated in Table 8.

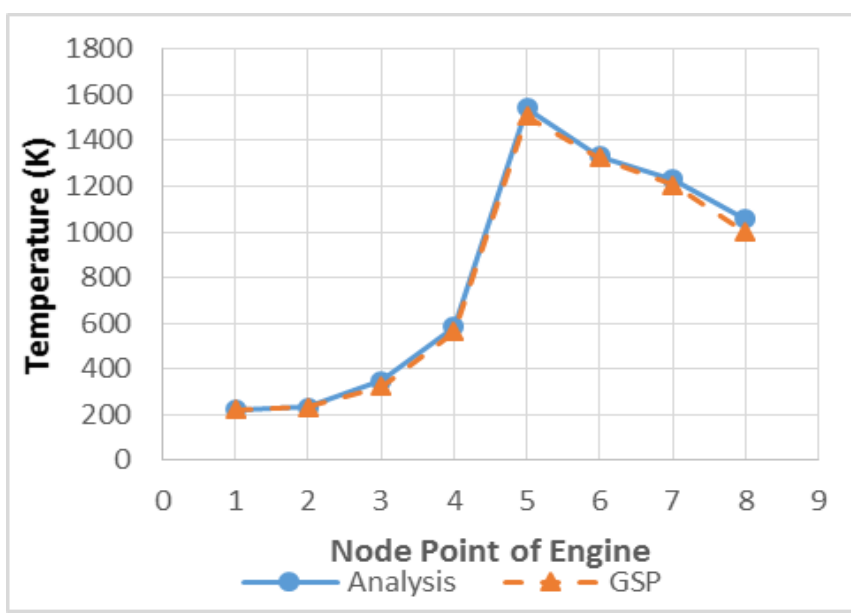

Fig. 9 Temperature variation along the engine components dual-spool engine

Table- IV. Temperature (K) variation at various nodes

\begin{tabular}{|r|r|r|r|}
\hline \multicolumn{1}{|c|}{ Node } & \multicolumn{1}{c|}{ Analysis } & \multicolumn{1}{c|}{ GSP } & \multicolumn{1}{c|}{ \% error } \\
\hline 1 & 223.3 & 223.3 & 0.000 \\
\hline 2 & 234.3 & 234.3 & 0.000 \\
\hline 3 & 348.47 & 324.54 & 0.074 \\
\hline 4 & 584.19 & 562.31 & 0.039 \\
\hline 5 & 1541.98 & 1504.72 & 0.025 \\
\hline 7 & 1333.53 & 1324.23 & 0.007 \\
\hline 8 & 1231.41 & 1204.94 & 0.022 \\
\hline & 1055.64 & 997.89 & 0.058 \\
\hline
\end{tabular}

\section{CONCLUSION}

After having tested the reliability of developed code for turbojet engine by comparison of analysis results with software simulation data, a good agreement can be concluded. The investigation also showed that a small error \% in results are found. This developed computer program possesses significant advantage over many earlier methods of digital engine simulation. Specifically, it eliminates the need to operate two separate computer programs to obtain steady-state results for single- and dual-spool turbojet engine. This saves money and man-hours when new engine models are to be simulated. Hence, this computer code for simulating the operation of turbojet engines allow the analyst to carry out many interesting calculations. The important results and conclusions are provided below:

1. The thrust produced by the engine increases with increase in Mach number and increase in mass flow rate of inlet air.

2. The TSFC is maximum when the pressure ratio is minimum and the TSFC is minimum when the pressure ratio is maximum for all the Mach number in this study.

3. The thermal efficiency decreases with increase in Mach number, whereas the overall efficiency increases with increase in Mach number. 
4. The power produced by the Turbine is over and above the power required to run the compressor.

Inclusion of the effect of heat transfer and volumetric dynamics into the present code will be necessary for further enhancing the effectiveness of the developed program.

\section{APPENDIX}

Using the developed program, further study on described engine was carried out. The graphs are plotted for various dependent performance parameters by changing variables.

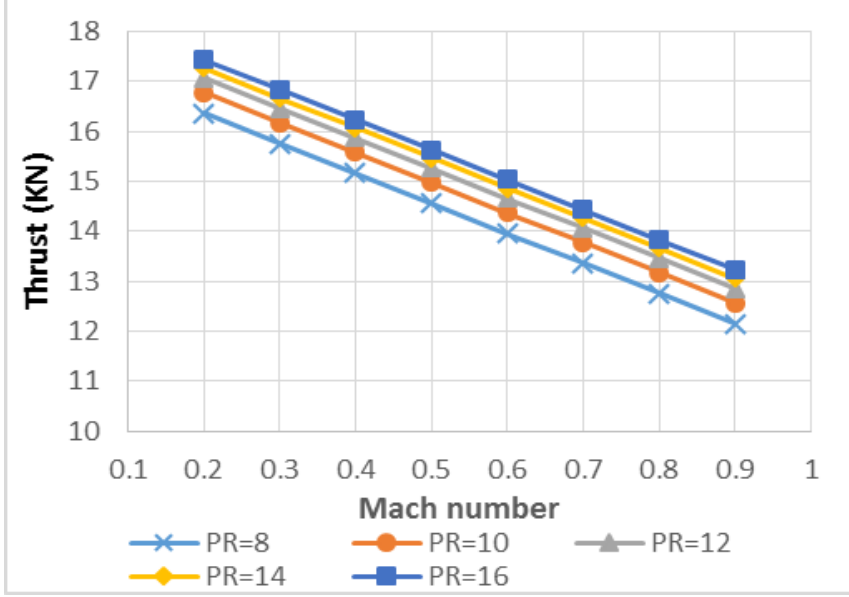

(a)

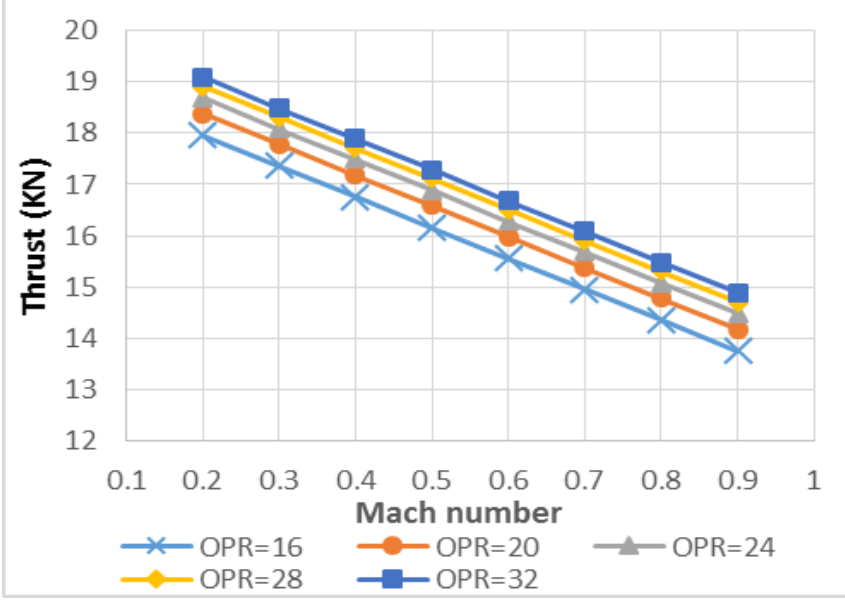

(b)

Fig. 12 Thrust at different Mach number and pressure ratio (PR) in single-spool (a) and dual-spool (b)

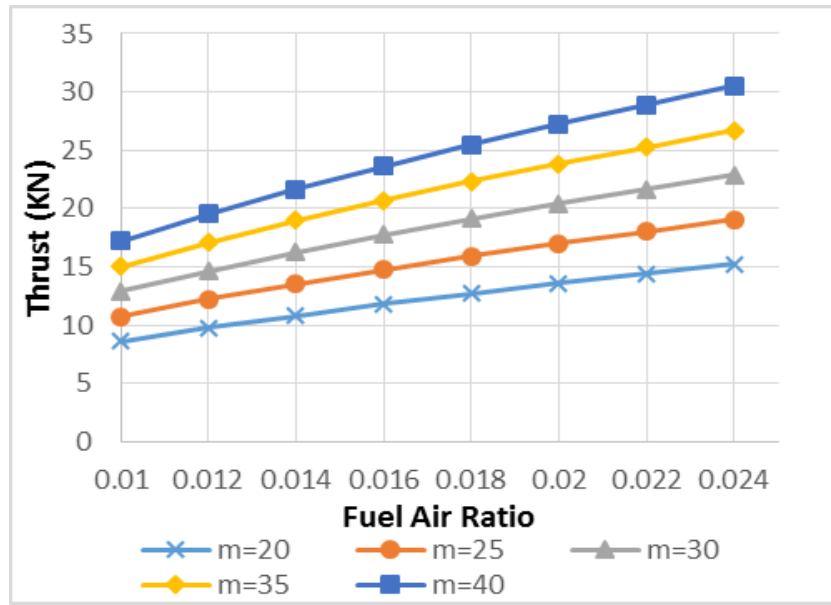

(a)

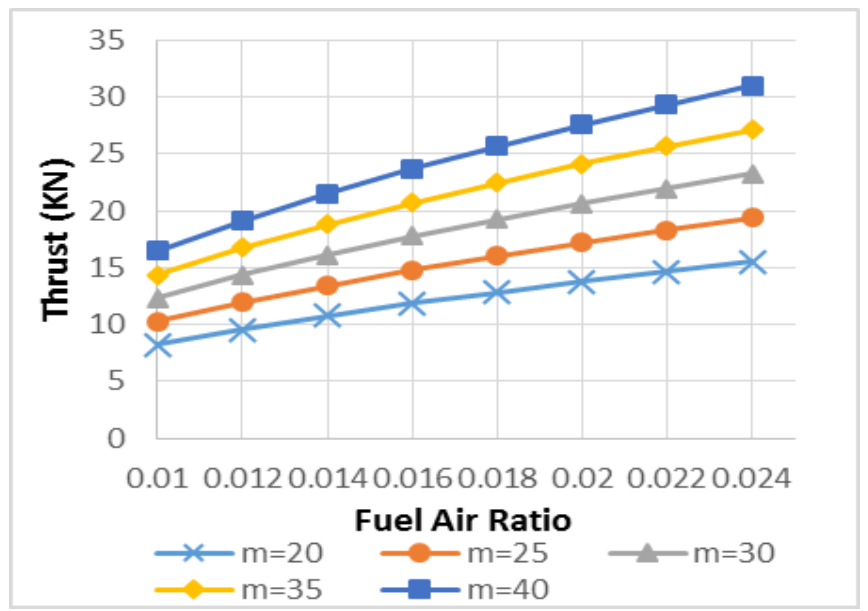

(b)

Fig. 13 Thrust at different fuel-air ratio and mass flow rate of air (m) in single-spool (a) and dual-spool (b)

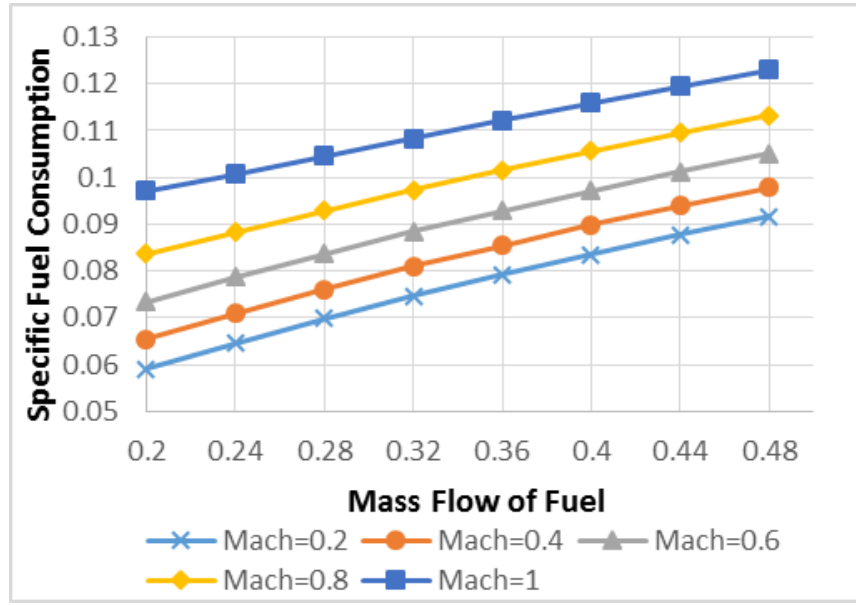

(a)

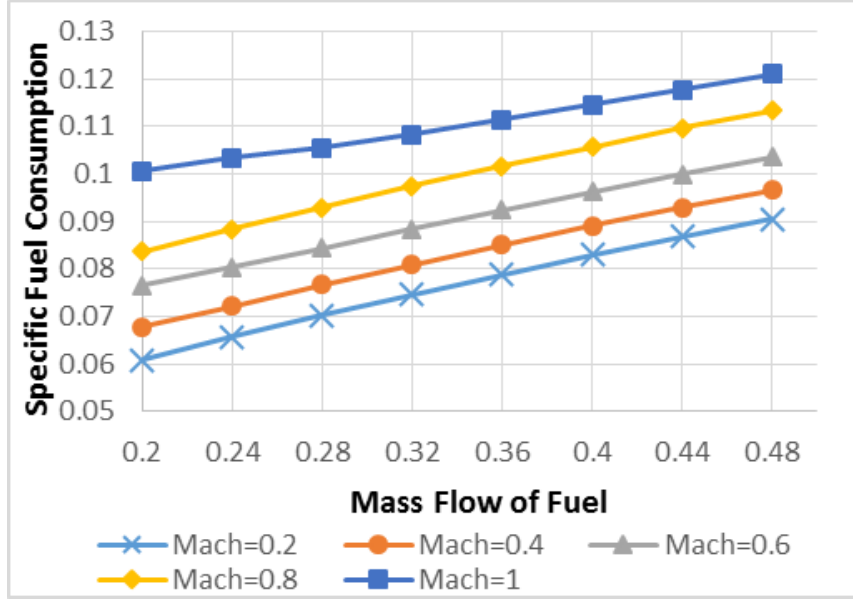

(b)

Fig. 14 SFC at different mass flow rate of fuel and flight Mach number in single-spool (a) and dual-spool (b)

\section{ACKNOWLEDGMENT}

The authors wish to thank the support and permission granted by NLR - Netherlands Aerospace Centre to use the Gas Turbine Simulation Program GSP 11 for carrying the analysis. 


\section{REFERENCES}

1. James F. Sellers and Carl J. Daniele, "DYNGEN- A Program for Calculating Steady-State and Transient Performance of Turbojet and Turbofan Engine", NASA TN D-7901, APRIL 1975.

2. HIH Saravanamuttoo, H.Cohen, GFC Rogers, "Gas Turbine Theory", Fifth Edition, Pearson, 2014, ISBN 978-81-7758-902-3.

3. Moaz Hussain "Numerical Analysis on Thermodynamic Performance of Simple Turbojet Engine", International Journal of Innovative Research in Technology (IJIRT), Volume 6, Issue 8, Page(s):61-65, January 2020.

4. Swati Chauhan, G. Jims John Wessley, "Thermodynamic Performance Analysis of a Micro Turbojet Engine for UAV and Drone Propulsion", International Journal of Recent Technology and Engineering (IJRTE), Volume-7, Issue-5S3, February 2019.

5. Saeed Farokhi, “Aircraft Propulsion”, Second Edition, John Wiley \& Sons, Ltd., May 2014, ISBN: 978-1-118-80677-7.

6. Jack D. Mattingly, "Elements of Gas Turbine Propulsion", Indian Edition, Tata McGraw-Hill Publishing Company Limited, New Delhi, 2014, ISBN-13:978-0-07-060628-9.

7. Philip G Hill, Carl Peterson, "Mechanics and Thermodynamics of Propulsion", Second Edition, Addison Wesley Longman, Inc., 1999 ISBN:0-201-52483-X

8. A.S. Rangwala, "Theory and Practice in Gas Turbines", New Age International (P) Limited, 2010, ISBN:978-81-224-2809.

9. Gitin M. Maitra, L. V. Prasad, "Handbook of Mechanical Design", Second Edition, Tata McGraw-Hill, 1985, ISBN: 0074517589.

10. Irwin E. Treager, "Aircraft Gas Turbine Engine Technology", Third Edition, Tata McGraw-Hill Publishing Company Limited, New Delhi, 2009, ISBN-13:978-0-07-463111-9.

11. Dinesh Kumar and R.K. Gupta, "Parametric and performance analysis of Turbojet engine through MATLAB", International Journal for Technological Research in Engineering (IJTRE) 3(10), pp.2653-2657, 2016.

12. Visser W.P.J., Oostveen M., Pieters H., Dorp E. van, "Experience with GSP as a Gas Path Analysis Tool", ASME GT2006-90904, ASME IGTI Turbo Expo conference, Barcelona 2006.

13. Visser W.P.J., Broomhead M.J., "GSP, A Generic Object-Oriented Gas Turbine Simulation Environment", ASME 2000-GT-0002, ASME IGTI Turbo Expo conference, Munich, 2000

\section{AUTHOR PROFILE}

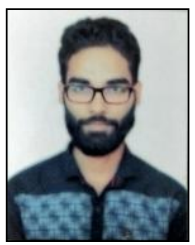

Moaz Hussain currently pursuing final year of BE. Degree in Aeronautical Engineering from Excel Engineering College, Tamil Nadu. Published papers in various international journal on Aerodynamic Optimization using CFD and Jet Engine analysis. Interested to join a challenging R\&D organization as a research scholar in the field of aerodynamics or jet engine integration to contribute in the development of technology 